\title{
The Impact of Cash Transfer on Family's attitude and Copying Mecanism
}

\begin{abstract}
The article studies the Impact of Cash Transfer on Family's attitude and SocialEconomy Development. The methodology of this study is mix methodology. Theoritical framework of this study is new institutionalism. The exercise field of this study is receiver of cash transfer in West Java and Bali. The paradigm of this research is departed from social fact and verstehen as the way of understanding and appreciation of a phenomenon socially, culturally, and economy in a deep consideration. A discourse on ideal type concept is a part of the study on 'objectivity' in the social scientific world. Ideal type conception directs a sociologist in developing his/her capability through guidelines to construct a hypothesis. Ideal type is hint a picture of reality but more to the aim of describing an ambiguous 'means of expression' in the picture. Empirical research attempts to comprehend a social phenomenon placing the observed events or actions with one or more ideal types. This study finds that capital, especialy social and economic capital, would be main key of cash transfer for success maintaining and developing societies. Quantity and Quality of capital decide opportunity for success and reward (trust) which is received. In other side, the form of Cash Transfer in economic action is mutual effect. Institutionalization of cash trasfer governance will impact on family's attitude and copyng mecanism.
\end{abstract}

Key words: Cash Transfer, Family's attitude, Copying Mecanism Communication

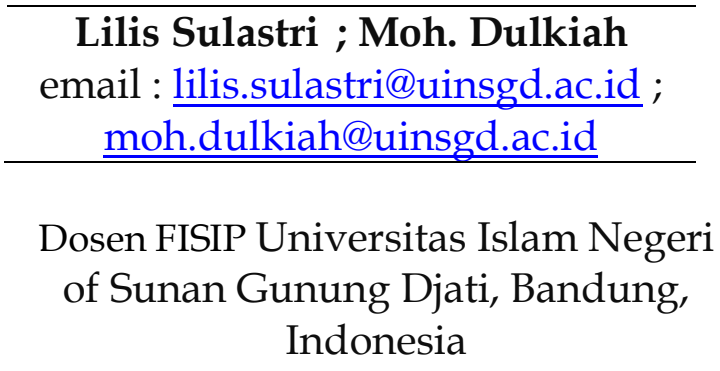

\section{A. Background}

This study focused on the Impact of cash transfer (CT) on Family's attitude and social-economy development. CT scheme aimed to reach one-third of Indonesian households to provide some compensation for the reduction in the fuel subsidy at a time of rapid fuel and food - particularly rice - price inflation. In the period of sixth president, cash was disbursed in several rounds in 2005-2006 and again in 2008-2009. CT attracted considerable negative public attention due to widespread protests, chiefly as a result of perceived inaccuracies in relation to beneficiary selection; some protests were violent, 
and the programe as a whole suffered from adverse public attention.

A number of cash payment schemes have been pursued in the Government of Indonesia's social assistance strategy over the last decade. The payment scheme is as follows: First, Program Keluarga Harapan (PKH). The program is a conditional $\mathrm{CT}$ program targeting the poorest families to receive cash between Rp.600,000 and Rp 2.2 million per year on the conditions of attendance at school children and accessing basic health services. The implementation of $\mathrm{PKH}$ carried out by taking experiments in 482,000 households in 7 provinces in 2007, has grown to 700,000 in 10 provinces, and is projected to reach about 3 million poor households by 2014; and second, Direct Cash Assistance (BLT). The BLT program is an unconditional cash payment intervention in 2005 and 2008 designed to protect the poor from the impact of fuel subsidies. BLT is targeted to more than 19 million beneficiaries through an annual cash payment of Rp100,000 which is disbursed every three months between October 2005 and September 2006, with an estimated cost of US \$ 2.4 billion. BLT was showed to protect beneficiaries similar to the 2008 fuel price hike.

The implementation of BLT has been linked to significant levels of social dissatisfaction, protests, and social conflicts, especially in 2005. Despite a small demonstration in 2008, public perceptions of CT scheme (especially BLT) are partially negative. There is a concern that CT has a negative impact on community participation. Government's antipoverty program, spe- cifically by crowding out participation in collective activities in the flagship community empowerment program, PNPM, or by encouraging indolence or -negativell forms of consumption (e.g. spending on tobacco or alcohol).

Evidence prior to this study suggests perceptions of wrong targeting and/or unfairness in beneficiary selection and other aspects of local implementation processes have been causes of discontent at the society level and among other potential beneficiaries. Organizational issues and problems with coordinating program delivery between different levels and agencies of government (particularly for BLT) appear to have been important sources of negative perceptions of CT programs among village (local) officials, community leaders, village heads, and other local elites. Other negative assumption that have featured among sourcerrs (local officials, political leaders). CT may lead to indolence and/or unwillingness among beneficiaries to exert themselves in collective or community-based activities. The other studies indicate that failures to adequately show the objectives and process of the BLT contributed to these perceptions. The negative perceptions have substantially subsided as more evidence and clarity about the programes have emerged. A recent report by the World Bank concluded that BLT had been reasonably effective and welltargeted, but that CT, particularly unconditional ones of this kind, 
remain susceptible to political manipulation (world bank, 2012).

To avoid the previous problems associated with BLT in potential future similar programs, or at least reduce and mitigate their impacts if they do occur, it is necessary to better understand how and why they occurred as a result of BLT and people perceptions of them.

\section{B. Method of Research}

The research questions are based on assumptions that: In light of a) the qualitative, process-oriented problem the study was attempting to understand, and b) the availability of several high quality evaluations of the impacts of BLT which account for how the program worked and why, a qualitative case study approach with comparative elements was adopted. This was judged to be necessary to make it possible to dig deeper into the social relational impacts. As the robustness of policy research is typically judged in terms of sample size, technical sophistication in the analysis process (usually econometric methods) and the use of quasiexperimental techniques, it is necessary to explain and justify the use of the qualitative comparative case approach, so that its claims to rigour and value-addition to the policy evidence base are clear (George and Bennett 2004; Gerring 2004; Booth 2008; Flyvbjerg 2011).

In order to frame the research questions and design, and to help inform the development of research instruments, a review of relevant literature was undertaken. There is a small literature on the wider social effects of social protection interventions, including of conditional cash transfers. In order to inform the research design and analysis, the literature review was composed of a series of mini-reviews of relevant thematic areas. Because the specific and diverse social structures, cultural forms, economic and political institutions and ecological conditions of the Indonesian archipelago are highly likely to influence the nature of the social effects of a program, the literature review focused, wherever possible, on evidence from Indonesia. Topic areas a.n: Coping strategies, particularly in relation to price shocks; The contribution of cash transfers to coping with economic shocks; The impacts of cash transfers on social relations;

A relatively recent body of literature focused on the poverty and social impacts of financial and commodity price shocks. This literature focused on large-scale or covariate shocks transmitting to national, regional or global levels and attempts to trace the effects of complex events such as banking and currency crises, their political aftershocks and fiscal adjustments, and commodity, food and production input price spikes.

There are no universal sequences according to which people adopt coping strategies. Calculations differ depending on what matters most to people in curent situations: in some contexts people priority preserving assets 
over nutrition or investments in human capital; in others, protecting social status means people avoid diversifying into demeaning types of work. Broadly, the continuum of copying strategies follows a sequence from the most resilient and least harmful (e.g. diversifying livelihood activities incl. migration) to permanent damage to people and family units (e.g. permanent withdrawal of children from education or risky livelihood activities), or failing to copé. Recent accounts from west Java and Bali, Indonesia show that these strategies mostly fall along the resilient end of the coping continuum including curbing or cutting consumption, particularly on non-essential items, migration, informal rather than formal employment or more women entering paid work (with implications for their unpaid care responsibilities). Because of their responsiveness and immediacy, informal and/or customary riskpooling and support mechanisms continue to play a - and very likely the most - significant role in protecting people against the worst effects of crises. This appears to be particularly true for Indonesia, but it may in part be an artefact of the rich anthropological and sociological literature on coping from the late 1990s crisis; however, protracted or severe collective crises are perceived to weaken the effectiveness of informal social protection arrangements.

\section{Result and Discussion}

CT has a number of advantages over other interventions in addressing shocks, including portability and relatively low administrative costs of distribution. These characteristics help cash-based deliver timely, popular responses at relatively low administrative cost. Technological innovations such as mobile phone-CT systems are rapidly improving the prospects for delivery.

In addition to being protective (providing relief), preventive (averting deprivation) and/or promotive (enhancing incomes and capabilities), social protection interventions can be -transformativell. Transformative objectives aim to address concerns of social equity and exclusion which often underpin people's experiences of chronic poverty and vulnerability. However, recent research points out that CT interventions are evaluated against their first order effects on poverty or human capital, with their impact on social relations within and between households typically more limited. Feeling shame of being poor and receiving social support, such as CTs, is a common theme. There is little known of whether stigma results from CTs in Africa or Asia, but evidence from female recipients of CTs in South Africa, indicate that these can help to alleviate the stigma associated with poverty rather than create it due to perceptions of creating dependency etc.

CTs can have positive as well as negative impacts on social capital. Evidence from Asia, Africa and South America shows that CTs can result in increased collaboration and trust at 
community level (e.g. through greater participation in community meetings, visits to health clinics - as part of conditions to receive benefits-or increased involvement in community saving initiatives) or more positive relationships due to a reduction in hunger, stress, begging or even reduced crime. However, this does not necessarily translate into an articulation of voice in local politics. CTs can have negative repercussions if the targeting is perceived to be unfair, as was seen with Indonesia's BLT.

What are the risks and vulnerabilities faced by people living in or in near poverty conditions in Indonesia? How are these distributed across geographical regions, social groups and time periods? Answering these questions is important in order to assess the nature, timing and distribution of need for support, whether cash-based interventions or other types of social protection, and to understand the patterns of coping strategies adopted by different groups under different conditions (see next section).

A participatory approach was taken to identifying the nature and distribution of risk and vulnerability across communities in the 11 provinces sampled in the study. The instruments were designed to enable people to see their own conditions and stressors, and so offer insights into how people themselves rank the risks they face, and into the patterns of vulnerability over time. Respondents were asked to describe the sources of and times during which they experience what they would consider to be crises or shocks. The responses included covariate, community-level and idiosyncratic shocks, and seasonal as well as oneoff events; many responses described sources of vulnerability rather than crises or shocks which had actually occurred, reflecting people's awareness of their own risk environment, and of their capacities for resilience when shocks do in fact strike. Responses from case study households and focus group discussions were triangulated through interviews and group discussions involving a social mapping exercise with the local leadership. These multiple sources permit insights into the nature of risk and vulnerability from diverse perspectives - women and men, younger and older, majority and minority groups, poorer and wealthier - and therefore offer a rounded and relatively robust picture of conditions and contexts.

In Bali, with living conditions that are difficult citizens, as mentioned above, they usually have a way to survive for the fulfillment of everyday household needs, namely: firstly, by way of owing to the stall in accordance with the needs it needs. And how to survive like this for people whose lives are difficult is commonplace. As the informants said, "debt to the stall is a normal thing if they are difficult for their household needs ...". The items that are usually owed are rice, sugar, spices and other kitchen needs. For the debt to the shop this is usually the 
do is women. Secondly, Owe to Group, Tempeh Group or Gapoktan (Combined Farmer Group) if they need money. Thirdly, applying loans to PKK through Women's Savings and Loans (SPP) activities. This loan is often done by members of the PKK group who are actually female. From this loan money will be used to buy the necessary needs. "Borrow money in PKK is usually done by mothers ... where the money is also to buy household needs ..." said the informant. Fourthly, For BLT recipients, usually they will save the need for rice in order to reduce the amount of debt in the stall.

Clearer patterns did emerge in relation to social-ecological context: communities with large transmigrant populations and relatively new rice-growing agricultural systems were more prone to crop failures, and environmental degradation was more evidently a concern in coastal, forest and hilly communities.

People who have poor and vulnerable form across these communities experience a wide range of shocks and risks, but natural disasters, environmental vulnerabilities and risks to natural resources are particularly prominent covariate crises. A policy implication may be that effective social protection approaches can usefully incorporate disaster risk reduction (DRR) within their design, to enable better prevention, coping and crisis management.

Natural and environmental resource degradation were major sources of vulnerability, particularly in locations where water sources were polluted or declining. Lack of water for agriculture, drinking and washing was a particularly common concern; this did not only reflect that the fieldwork took place during the dry season, but also appeared to illustrate more sustained declines in water resources, pollution from agricultural, industrial or infrastructural development.

Seasonal change remain common in rural areas, where people are dependent on crops and products or on predictable weather patterns; Crop failures due to weather and pestilences are the single most commonly cited type of risk, highlighting the need to connect rural social protection systems with agricultural extension services that support sustainable practices and environmental protection; Fuel, food and agricultural input price rises are widely noted as a concern, but not usually the most important shock or crisis experienced; Horizontal conflict was a latent source of tension, creating vulnerabilities in relation to land tenure in particular; violent conflict in West Java and Bali had direct and enduring effects on livelihoods and perceptions of risk; in West Java and Bali, relations between indigenous people and transmigrants were tense; in almost all communities.

The private sector featured as a source of vulnerability when companies withdrew from the area, but also in terms of unregulated environmental damage and buying local agricultural land for non-farm uses; brokers (of fish or other agricultural commodities) were often 
cited as helping to spread and therefore risk, as were employers in a small number of cases.

People were also asked to describe their methods and strategies for managing the risks and vulnerabilities they face. The responses were again triangulated across multiple sources. Unlike shocks and vulnerabilities, which were more likely to be covariate than idiosyncratic, coping mechanisms tend to center around the household. However, an important finding, which affirms much of the literature on coping mechanisms in Indonesia ${ }^{9}$ is that the success of household coping mechanisms depends substantially on the nature and quality of the social networks and relationships within which they are embedded. This is particularly true of the customary institutions and local community arrangements for managing risk, but also to some extent of whether and how people benefit from CTs and other official social protection and community development schemes.

Analysis of the findings about how people cope with shocks and vulnerabilities show that these are of four broad types:

Diversifying livelihoods, including short-term activities to increase or protect incomes such as taking on additional jobs or new working or production practices; women are particularly likely to involve themselves in petty trading and service sectors in times of crisis. Diversification also includes more enduring adaptation strategies to respond to perceived structural shocks or economic change (e.g., migration, entering new sectors, dropping out of education, cultivating rice as opposed to hunting)

Consumption conservation, in particular cutting down on quality or quantity of food and/or everyday consumption goods such as cigarettes or children's pocket money

Borrowing, most usually soft loans from relatives and kiosks, but also under duress, from other sources such as moneylenders and cooperatives, or from brokers (of fish or commodities) or employers

$\square$ Sales of assets (land, but also tools) and consumer goods such as electronics or jewellery which have resale value.

People took on a range of different short-term occupations to cope with shocks, including selling food items, working as wage workers, and providing domestic and related services. Agricultural diversification involved moving from crops experiencing frequent failure to different products, including cash crops, poultry or other livestock.

The research involved an exercise to enable people to show their own consumption conservation 
aattitude. This showed that to cut on the costs of consumption, people commonly stated that they would cut down on non-essentials first, such as condiments, cigarettes and other luxuries. Men reported that they were likely to cut down on quality and quantity, and in some (relatively rare) cases to cut out smoking altogether. Few poor people ate meat on a regular basis, but that would also be an item to cut in hard times. Rice consumption tended to be protected first and foremost, although there were very poor people who had undergone severe distress who had had to replace rice with cassava.

Sources of support. The research documented and facilitated analysis of the sources of support on which people were able to call in times of need. In line with the core research assumptions, the approach was to identify all types of support, whether informal or formal, and all forms these took. The two-step approach involved enabling a listing and analysis of all of the important institutions that provided support, and then a matrix ranking to analise which types of support were most valued, and why. The matrix ranking exercise asked people to score the different sources of support they had already identified along pre -set categories, including timeliness, fairness, the value of the support, availability of information about the support, fit with needs, and capacity to participate or influence the type or form of the support. As the matrix ranking exercise was not used in the same way in all sites, the results from the exercise are indicative, and are interpreted together with interview and focus group discussion findings.

According to informants, there is a habit of gotong royong (work coperation) run by all citizens, where no matter rich or poor all citizens will be involved. Banjar is a form of work coperation where all villagers, although different groups are required to get involved. Although there is no sanction if not involved will be the spotlight of the community. In this grief the activities include religious ceremonies that are present in the form of birth ceremonies, marriage and death and other ceremonies. And this mechanism has been running since a long time as a way to relieve the citizens in carrying out these ceremonies, which turned out to cost a lot. Because of the high cost of the ceremony, sometimes for some poor people can't bear the cost. So with this sadness this problem can be solved because the people who come will donate money.

Social relations in community were mediocre. There are some who help each other and please help with others, but there are also arrogant and difficult to cooperate. One of informant said that community is good but some are less helpful. Mediocre depends on us. But if related to the help-help in the economic field as knowledge of informants decreased. Society is not what it used to be. The sense of kinship and neighborhood has 
diminished. But Informant also said that in his RW there is still a communication relationship among the citizens.

Social conflicts in society due to errors in the determination of persons eligible to receive BLT are not physical. According to him, people accept because this can be BLT is indeed a person who is entitled to receive it. But according to informants: "If the BLT recipient is properly and professionally recorded, he said, then the aid will be hit.

The impact of BLT on other programs is not directly related, for example, because BLT finally gets good social relations or participation increases. BLT does not directly interfere with or interfere with other programs / assistance. BLT is only utilized by the recipient's individual / family and does not interfere with other programs / assistance. However, when compared to other programs / assistance, BLT is the most common problem. While the most beneficial program is raskin because it gives more benefit to the poor more broadly.

From the discussions around the matrix ranking exercises, several issues emerged around the kinds of support people prefer during periods of crisis:

Whether food, cash infrastructure or equipment (including sanitation, water, and housing) were preferred as sources of support depended on the most serious vulnerabilities people were facing: there were no distinct patterns across the provinces or communities, nor between the genders

Rice investments and subsidies in public infrastructure, housing or support for livelihoods were preferable as longer-term and providing more predictable sources of support. Several people felt that if BLT amounts were increased the effects would be developmental rather than merely supporting welfare

People able to access the source of support as and when it is needed - or timeliness - is critical to how it is perceived. Accessibility, lack of (or little) shame, and explain why borrowing from family was widely cited as the most important source of support

Other informal sources of support at the community or group level were also important. Arisans offered a valued form of savings and social inclusion, although some of the very poorest were excluded or self-excluded because of the need to make regular payments. Community rice storage systems helped secure rice supplies in rice growing areas. Collective work arrangements helped people invest in their land or repair or build homes. And expensive times such as weddings or 
funerals (although not educational costs) are often supported by more or less compulsory universal contributions. This tended to be more true in rural than urban communities, which lacked some institutions of social cohesion. But both socially diverse and more homogenous communities, and original inhabitants and settler groups, generally featured some collective forms of social support

When people have difficulty meeting their needs, they usually benefit from some sources of help. From the sources of assistance identified by the participants, based on their form, there appears to be several diverse trends, as well as the results of the scoring matrix by the facilitator. In the scoring matrix, the facilitator identifies some sources of assistance that participants get when they experience difficult conditions, among them: First, the shop. Participants usually often debt in stalls. Made mentioned that if bombing in a shop usually owes rice. In addition to rice they also like the debt of children's food snacks. Children usually often take first food or snacks at the stall. In addition, they like to owe vegetables or side dishes and spices at the stall.

The participants consider that the stall is quicker. They reasoned that the shop has become a daily shopping subscription so there are already customs and beliefs. But the stalls have weaknesses because the form of assistance only merchandise, especially rice and daily necessities such as spices, cigarettes, sugar, coffee, and snacks of children. While other fastassumed help is out. The participants reasoned that the loans to the family have been accustomed to ever since. The participants argue that borrowing to this family is also considered quick and easy to do because if the family borrowed already know each other and not shy anymore.

Families usually know the condition of the family when they have money and whether or not. But the easiest way to convey the complaint is the shop because it is considered close and no doubt anymore. Stalls are considered the most vulnerable because there is a relationship between subscribers and stall owners, so they usually receive all our complaints and suggestions, most importantly when the participants borrow the goods there.

From the aspect of justice, the participants think that borrowing to the stalls, family, and raskin is considered the same level of justice. While the daily bank is the type of aid that is considered the most unfair because of the large percentage interest. They did not dare to borrow it to this daily bank. Related to benefit aspect, discussion participants acknowledge the source of aid from stall is considered the most benefit. Similarly, families because they are 
often given assistance in the form of loans, then considered the participants have benefits.

\section{Conclusion}

Cash transfer that became one model of poverty reduction strategy has a diverse effect among the community. People who can manage finances well in the family, cash transfer has good benefits. This assistance can change the lives of recipient families. Beneficiaries can save and determine needs according to priority needs. As for the people who can not manage the good, they are stuck in an excessive life. BLT, $\mathrm{PKH}$, and others help only temporarily. This assistance can even create problems for their families in the future after their families receive no further assistance.

\section{E. References}

Adams L. and E. Kebete. 2005. Breaking the Poverty Cycle: a Case Study of Cash Interventions in Ethiopia, Background Paper, Humanitarian Policy Group, London: Overseas Development Institute.

Bailey, S., Savage, K. and S. O’Callaghan. 2008. Cash transfers in emergencies. A synthesis of World Vision's experience and learning. World Vision International.

Cross, T. and A. Johnston. 2011. Cash transfer programming in urban emergencies. A toolkit for practitioners. CaLP.
Devereux, S. and Jere, P. 2008. Choice, Dignity and Empowerment. Cash and Food Transfers in Swaziland. An evaluation of Save the Children's Emergency Drought Response, 2007/08.

Gentilini, U. 2007. Cash and Food Transfers: A Primer. Rome: World Food Programme.

Grindle, Merilee S. 2011. 'Governance Reform: The New Analytics of Next Steps', Governance 24(3): 415-418.

Hanlon, J., Barrientos, A. and D. Hulme. 2010. Just give money to the poor. The Development Revolution from the Global South. Kumarian Press. 